\title{
Estimation of Global Solar Radiation in Mubi, Nigeria
}

\author{
Ogbaka D.T ${ }^{*}$, Bassi $\mathrm{H}^{2}$, Lami D.S ${ }^{3}$ and Tahir M.A \\ ${ }^{1}$ Department of Pure and Applied Physics, Adamawa State \\ University, Mubi, Adamawa State, Nigeria. \\ 2Department of Computer Science \\ Modibbo Adama University of Technology, Yola. Adamawa State. \\ ${ }^{3}$ Department of Information Technology \\ Modibbo Adama University of Technology, Yola. Adamawa State. \\ ${ }^{4}$ Department of Science Laboratory Technology, College of Science and Technology \\ Adamawa State Polytechnic, Yola. Adamawa State. \\ *Corresponding author details: Ogbaka D.T.; dtogbaka@gmail.com

\begin{abstract}
Application of solar energy system requires having knowledge about solar irradiation potential in different locations. This study therefore used artificial neural networks for predicting solar global radiation by using metrological data. There is no report about prediction of solar radiation potential for Mubi by using Artificial Neural Network (ANN) method. It is very encouraging to observe a very fine agreement between the measured and estimated values shown in study. The ANN Model is considered the best relation for estimating the global solar radiation intensity for Mubi region with an acceptable error. The MSE, RMSE, MBE, MABE and MAPE values are $0.930,0.964,0.3358 \mathrm{MJm}-2$ day-1, $0.8175 \mathrm{MJm}-2$ day-1 and $19.30 \%$, respectively. The ANN models appear auspicious for estimating the Global Solar Radiation in the locations where there are no solar radiation measurement stations.
\end{abstract}

Keywords: solar radiation; artificial neural network; renewable energy; multi-layer perception; Mubi

\section{INTRODUCTION}

An accurate knowledge of solar radiation distribution at a particular geographical location is of vital importance for the development of many solar energy devices. Unfortunately, for many developing countries solar radiation measurements are not easily available due to the shortage of measurement equipment's (Okundamiya and Nzeako, 2010). It is therefore important to consider methods of estimating the solar radiation using Artificial neural networks on the readily available meteorological parameters.

When building the Artificial Neural Network model, the process has to be identified with respect to the input and output variables that characterise the process. The inputs include measurements of the physical dimensions, measurements of the variables specific to the environment and equipment and controlled variables modified by the operator. Three types of networks used most commonly in ANN applications are feed forward networks, competitive networks and recurrent associative memory networks. A practical description of ANN methods with sample applications was presented in Hagan, Demuth and Beale (1997).

Many of the building energy systems are exactly the types of problems and issues for which the artificial neural network (ANN) approach appears to be most applicable.
Neural networks have the potential for making better, quicker and more practical predictions than any of the traditional methods. The performance of a building energy system depends on the environmental conditions such as solar radiation and wind speed, the direction, strength and duration of which are highly variable (Kreider and Wan, 1991).

\section{MATERIALS AND METHOD}

The monthly mean daily data for sunshine hours were obtained from Department of Geography metrological unit situated in Adamawa State University, Mubi. The data obtained covered a period of five years $(2009-2013)$ for Mubi, Nigeria located on latitude $10.2667^{\circ} \mathrm{N}$ and longitude $13.2667^{\circ} \mathrm{E}$

The Angstrom- Prescott regression equation which has been used to estimate the monthly average daily solar radiation on a horizontal surface in Nigeria or other places is given as:

$$
\frac{H_{m}}{H_{o}}=\left[a+b \frac{s}{S_{o}}\right]
$$

$H_{m}$ is daily mean values of global radiation $\left(\mathrm{MJm}^{-2} \mathrm{day}^{-1}\right)$, $S_{o}$ the daily average value of day length, and ' $a$ ' and ' $\mathrm{b}$ ' values are known as Angstrom constants and they are empirical. 
$\mathrm{H}_{\mathrm{o}}$ is daily mean values of extraterrestrial radiation (MJm${ }^{2}$ day- $^{-1}$ ), calculated using equation (2) as described by Prescott, (1940).

$H_{o}=\frac{24 \times 3,600}{\pi} I_{S c} E_{o}\left[\cos (\varphi) \cos (\delta) \sin \left(\omega_{s}\right)+\right.$

$\left.\frac{\pi \omega_{s}}{180} \sin (\varphi) \sin (\delta)\right]$

$I_{s c}=\frac{1,367 \times 3,600}{1,000,000} \mathrm{MJm}^{-2} \mathrm{day}^{-1}$

$\mathrm{I}_{\mathrm{s}}$ the solar constant, The units in $\mathrm{kWhm}^{-2} \mathrm{day}^{-1}$

$E_{o}$ represents the eccentricity correction, and described using Eq. (3.4) in Eq. 3.2

$E_{o}=1+0.033 \cos \frac{360 n_{d}}{365}$

$\mathrm{n}_{\mathrm{d}}$ is the day number of the year /Julian day ( 1 Jan, $\mathrm{n}_{\mathrm{d}}=1$ and $31^{\text {st }}$ December, $n_{d}=365$ ), $\varphi$ is the latitude of the site, $\delta$ the solar declination and, $\omega_{\mathrm{s}}$, the mean sunset hour angle for the given month. The solar declination $(\delta)$ and the mean sunset hour angle $\left(\omega_{s}\right)$ can be calculated as suggested by Duffie and Beckman, (1991):

$\delta=23.45 \sin 360 \frac{284+n_{d}}{265}$

$\omega_{s}=\cos ^{-1}(-\tan \varphi \tan \delta)$

For a given day, the maximum possible sunshine duration (monthly values of day length, $\left(S_{o}\right)$ can be computed by using Cooper's formula (1969):

$S_{o}=\frac{2}{15} \cos ^{-1}(-\tan \varphi \tan \delta)$

For a given day, the maximum possible sunshine duration (monthly values of day length, $(\mathrm{N})$ can be computed by using (Duffie and Beckman, 1991):

$N=\frac{2}{15} \omega_{S}$

\section{Application of Artificial Neural Network}

A feed-forward back-propagation neural network was used in this study. A typical neural network consists of an input, a hidden, and output layer. Other components include a neuron, weight, and connections or transfer function as shown in Figure 1 and Figure 2.

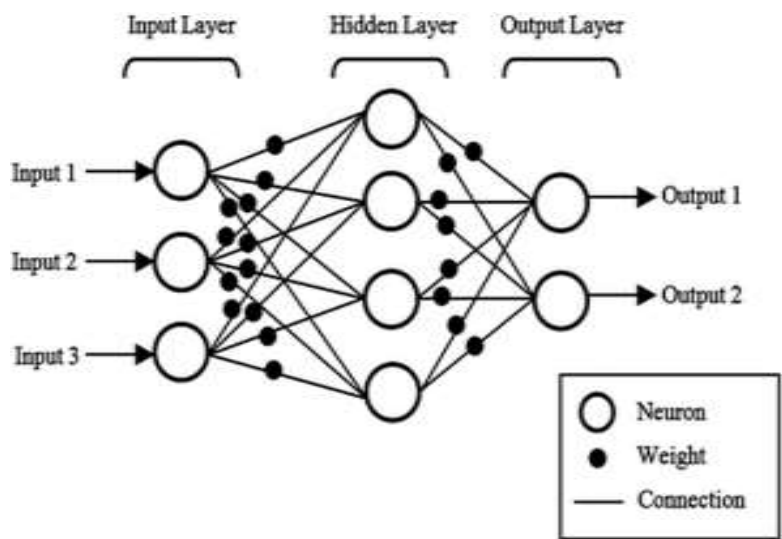

FIGURE 1: A typical neural network for filtration

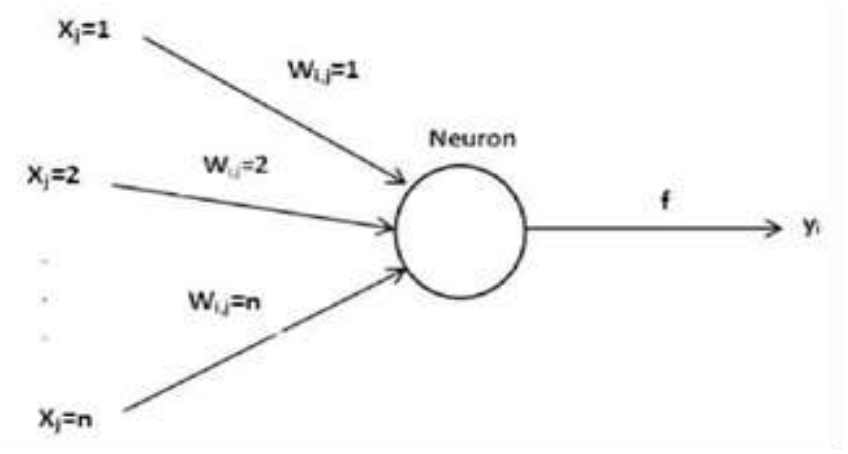

FIGURE 2: Feed forward neural network

The values of $X_{1} ; X_{2}, X_{n}$ are inputs and $W i, W_{2}, W_{n}$ are weights. Each input is multiplied by the relevant weight. Obtaining products and bias are summarized. By applying activation function to the result of summary, the output of neuron is obtained. There are three steps in solving an ANN problem which are 1) training 2) generalization and 3 ) learning. Training is a process that network learns to recognize present pattern from input data set together with the desired pattern of activities for the output units. Generalization or testing evaluates network ability in order to extract a feasible solution when the inputs are unknown to network and are not trained to network. We determine how closely the actual output of the network matches the desired output in new situations. In the learning process the values of interconnection weights are adjusted so that the network produces a better approximation of the desired output. The disadvantage is that its operation can be unpredictable, because the network finds out by itself how to solve the problem.

Figure 1 shows the block diagram of a single hidden layer multiplayer perceptron (MLP). The inputs are fed into the input layer and get multiplied by interconnection weights as they are passed from the input layer to the hidden layer. Within the hidden layer, they get summed then processed by a nonlinear function (usually the hyperbolic tangent). If more than a single hidden layer exists then, as the processed data leaves the first hidden layer, again it gets multiplied by interconnection weights, then summed and processed by the second hidden layer and so on. Finally, the data is multiplied by interconnection weights then processed one last time within the output layer to produce the neural network output. To perform any task, a set of experiments of an input output mapping is needed to train the neural network. These data are one of the most important factors to obtain reliable results from any trained ANN. Thus, the training sample data have to be fairly large to contain all the required information and must include a wide variety of data from different experimental conditions and process parameters.

\section{Statistical evaluation}

The performance of the models was evaluated on the basis of the following statistical parameters such as Mean Square Error (MSE), Root Mean Square Error (RMSE), Mean Bias Error (MBE), Mean Absolute Bias Error (MABE) and Mean Absolute Percentage Error (MAPE).

$$
\begin{aligned}
& M S E=\left(\left[\frac{\sum\left\{H_{i, c}-H_{i, m}\right\}^{2}}{N}\right]\right)\left(\mathrm{MJm}^{-2} \mathrm{day}^{-1}\right) \\
& R M S E=\left(\left[\frac{\sum\left\{H_{i, c}-H_{i, m}\right\}^{2}}{N}\right]\right)^{1 / 2}\left(\mathrm{MJm}^{-2} \text { day }^{-1}\right) \\
& M B E=\left(\left[\frac{\sum\left\{H_{i, c}-H_{i, m}\right\}}{N}\right]\right)\left(\mathrm{MJm}^{-2} \mathrm{day}^{-1}\right) \\
& M A B E=\left|\left(\left[\frac{\sum\left\{H_{i, c}-H_{i, m}\right\}}{N}\right]\right)\right|\left(\mathrm{MJm}^{-2} \text { day }^{-1}\right) \\
& \left.M A P E=\left|\left(\left[\frac{\sum\left\{H_{i, c}-H_{i, m}\right\}}{N}\right] \times 100\right)\right| \text { (percentage }\right)
\end{aligned}
$$


The RMSE provides information on the short-term performance of the correlations by allowing a term-byterm comparison of the deviation between the calculated and measured values. The values of the MBE represent the systematic error or bias, a positive value of MBE shows an over-estimate while a negative value an under-estimate by the model. The MABE gives the absolute value of bias error and it is a measure of the correlation goodness. The MPE is an overall measure of forecast bias, computed from the actual differences between a series of forecasts and actual data point observed; each difference is expressed as a percentage of each observed data point, then summed and averaged.
The MAPE is an overall measure of forecast accuracy, computed from the absolute differences between a series of forecasts and actual observed data. The disadvantage associated with MBE and MPE is that errors of different signs may cancel each other, the smaller the value, the better the model performs, but some few values in the sum can produce a significant increase in the parameter. The MBE and MPE offering information regarding overestimation or underestimation of estimated data; low values of these mean errors are desirable, though it should be noted that overestimation of an individual data element will cancel underestimation in a separate observation.

\section{RESULTS AND DISCUSSION}

TABLE 1: Metrological data and Global Solar Radiation for Mubi

\begin{tabular}{cccccccc}
\hline Month & $\overline{\boldsymbol{S}}(\mathbf{h r})$ & $\overline{\boldsymbol{S}}_{\mathbf{o}}(\mathbf{h r})$ & $\overline{\boldsymbol{S}} / \overline{\boldsymbol{S}}_{\mathbf{o}}$ & $\boldsymbol{H}_{\boldsymbol{m}}$ & $\boldsymbol{H}_{\boldsymbol{o}}$ & $\frac{\boldsymbol{H}_{\boldsymbol{m}}}{\boldsymbol{H}_{\boldsymbol{o}}}$ & $\frac{\boldsymbol{H}_{\boldsymbol{e}}}{\boldsymbol{H}_{\boldsymbol{o}}}$ \\
\hline Jan & 6.26 & 12.55 & 0.58 & 21.42 & 39.41 & 0.54 & 0.53 \\
Feb & 5.92 & 7.01 & 0.84 & 22.32 & 27.95 & 0.79 & 0.76 \\
Mar & 7.61 & 13.56 & 0.64 & 23.89 & 39.70 & 0.60 & 0.65 \\
Apr & 5.48 & 12.54 & 0.53 & 22.39 & 33.67 & 0.66 & 0.56 \\
May & 6.18 & 12.55 & 0.57 & 21.20 & 39.28 & 0.53 & 0.59 \\
Jun & 5.42 & 12.54 & 0.43 & 19.62 & 33.87 & 0.57 & 0.47 \\
Jul & 5.12 & 12.55 & 0.42 & 19.05 & 39.14 & 0.48 & 0.47 \\
Aug & 5.22 & 12.55 & 0.40 & 17.67 & 37.71 & 0.46 & 0.45 \\
Sep & 5.62 & 12.54 & 0.45 & 18.67 & 33.81 & 0.55 & 0.52 \\
Oct & 5.81 & 12.55 & 0.46 & 19.39 & 39.54 & 0.49 & 0.52 \\
Nov & 5.75 & 12.54 & 0.45 & 19.47 & 33.76 & 0.57 & 0.54 \\
Dec & 4.97 & 12.55 & 0.48 & 19.60 & 39.34 & 0.49 & 0.48 \\
\hline
\end{tabular}

TABLE 2: Estimation of monthly average daily global solar radiation for Mubi

\begin{tabular}{ccccc}
\hline Month & $\mathbf{H}_{\mathbf{m}}$ & $\mathbf{H o}_{\mathbf{o}}$ & He & ANN \\
\hline Jan & 21.42 & 39.41 & 21.06 & 22.06 \\
Feb & 22.32 & 27.95 & 21.27 & 22.00 \\
Mar & 23.89 & 39.70 & 26.13 & 23.60 \\
Apr & 22.39 & 33.67 & 19.12 & 21.50 \\
May & 21.20 & 39.28 & 23.31 & 22.98 \\
Jun & 19.62 & 33.87 & 16.18 & 18.40 \\
Jul & 19.05 & 39.14 & 18.66 & 17.98 \\
Aug & 17.67 & 37.71 & 17.27 & 16.04 \\
Sep & 18.67 & 33.81 & 17.60 & 18.97 \\
Oct & 19.39 & 39.54 & 20.67 & 19.56 \\
Nov & 19.47 & 33.76 & 18.52 & 18.52 \\
Dec & 19.60 & 39.34 & 19.05 & 19.05 \\
\hline
\end{tabular}

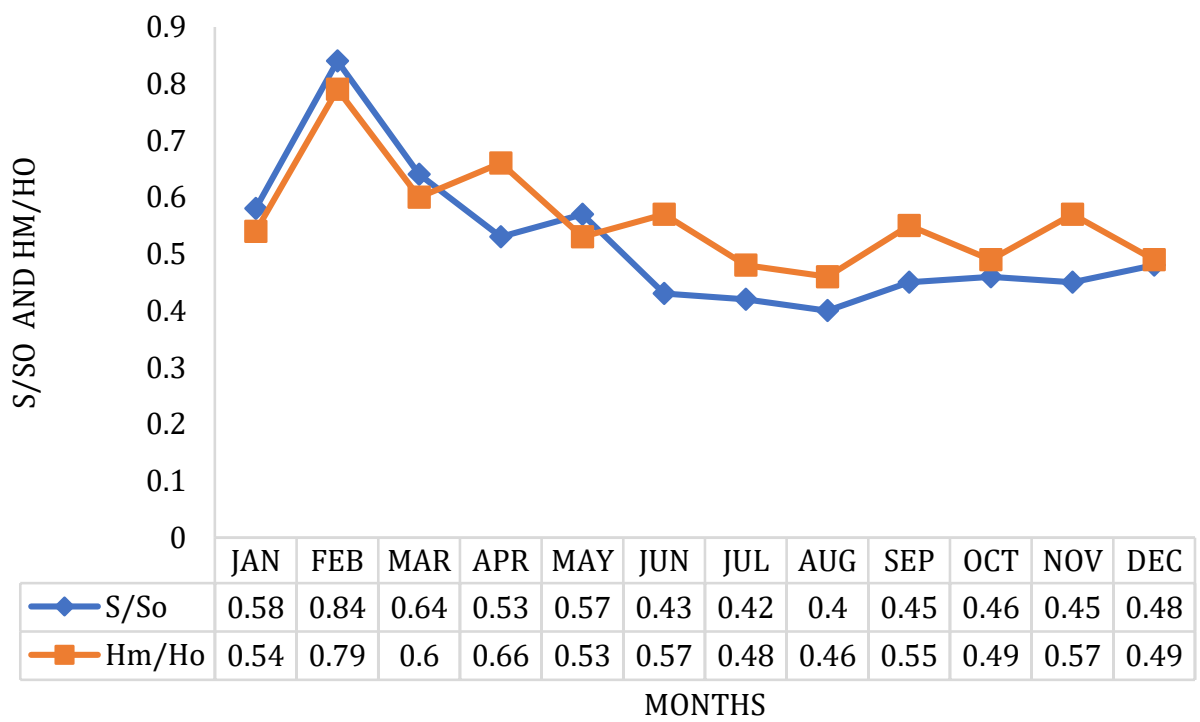

FIGURE 1: Variation of $S / S_{o}$ and $H_{m} / H_{o}$ (The clearness index) 


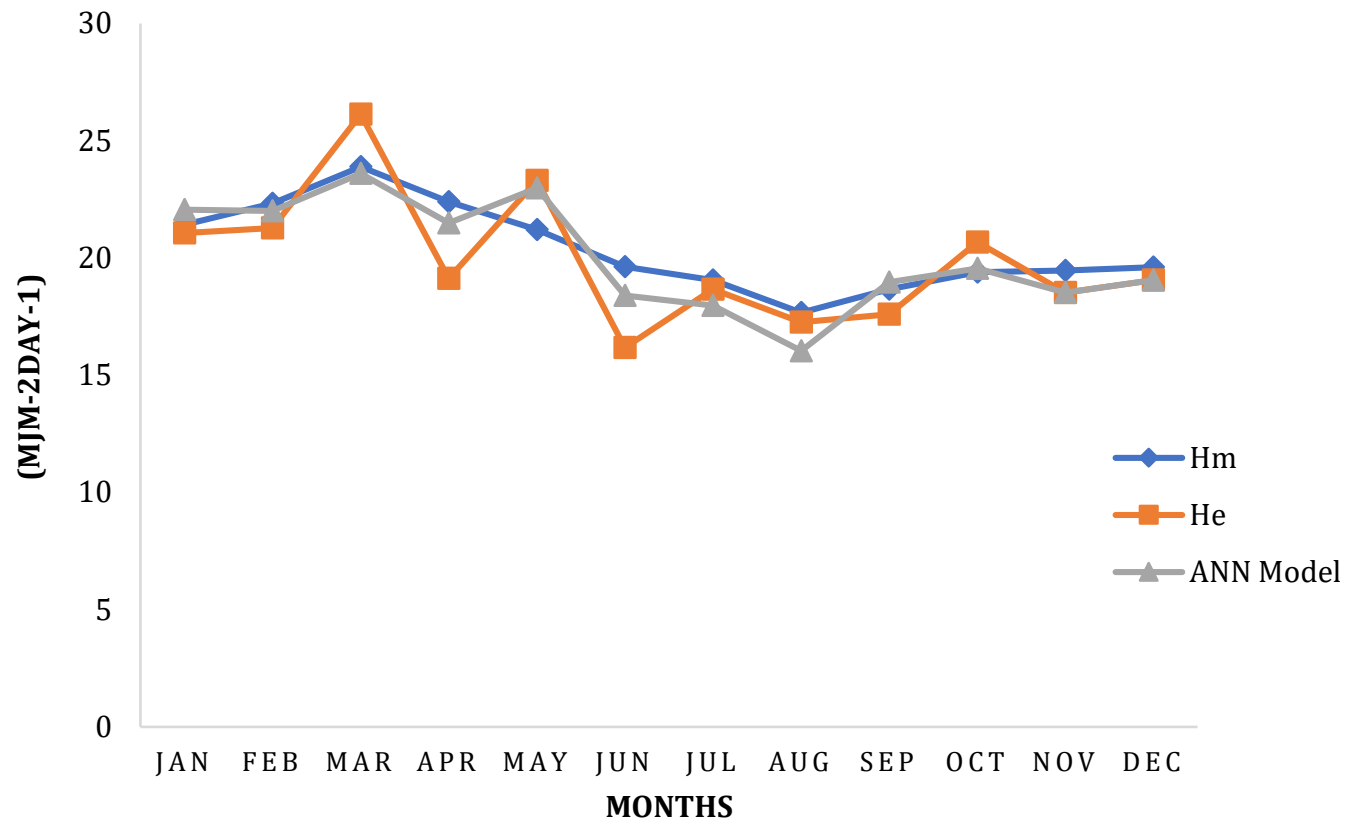

FIGURE 2: Estimated, measured and ANN model of GSR

TABLE 3: Statistical results of different models. MSE, RMSE, MBE, MABE and MAPE computed in the comparison between observed and estimated daily solar radiation.

\begin{tabular}{|c|c|c|}
\hline Statistical Results & Estimated model & ANN model \\
\hline MSE & 3.127 & 0.930 \\
\hline RMSE & 1.768 & 0.964 \\
\hline MBE & 6.8484 & 4.1029 \\
\hline MABE & 0.4875 & 0.3358 \\
\hline MAPE & 1.4258 & 0.8175 \\
\hline
\end{tabular}

Table 1 and figure 1 shows the value of $\mathrm{H}_{\mathrm{e}} / \mathrm{H}_{\mathrm{o}}(=0.45)$ corresponding to the lowest value of $\mathrm{S} / \mathrm{S}_{\mathrm{o}}(=0.40)$ and $\mathrm{H}_{\mathrm{e}}$ $\left(17.27 \mathrm{MJm}^{-2}\right.$ day $\left.^{-1}\right)$ in the month of August is an indication of poor sky condition. These conditions correspond to the general wet or rainy season (June - September) observed in Nigeria, during which there is much cloud cover.

The monthly average daily global solar radiation was estimated through equations (1) to (8) for Mubi from the two models used in the study are given in Tables 1-2, along with the measured values, are also plotted with the measured data in figure 2 . It is very encouraging to observe a very fine agreement between the measured and estimated values shown in Table 2.

The ANN Model is considered the best relation for estimating the global solar radiation intensity for Mubi region with an acceptable error. The MSE, RMSE, MBE, MABE and MAPE values are 0.930, 0.964, 0.3358 $\mathrm{MJm}^{-2}$ day $^{-1}, 0.8175 \mathrm{MJm}^{-2}$ day $^{-1}$ and $19.30 \%$, respectively. The ANN models appear auspicious for estimating the Global Solar Radiation in the locations where there are no solar radiation measurement stations.

\section{CONCLUSION}

Solar energy has an important role in economic development of Nigeria, since energy plays an important role in determining the conditions in which living matter can exist. Thus, it becomes apparent that artificial neural networks are more in harmony with measured global solar radiation, but both have potential estimates. Artificial neural network model can therefore be used to forecast global solar radiation at Mubi and other locations with similar climatic conditions. For further study, it is considered to develop prediction model for many locations of Adamawa State and Nigeria. This study plan can be introduced neural network technique for modeling the spatial variation of global solar irradiation in Nigeria. 


\section{REFERENCES}

[1] Cooper, P.I (1969). "The Absorption of Radiation on Solar Stills”, Solar Energy, vol. 12, no. 3, pp 333 - 346.

[2] Duffie, J. A. and Beckman, W. A., (1991). Solar Engineering of Thermal Processes, $2^{\text {nd }}$ edition, New York: Wiley.

[3] Hagan M.T, Demuth H.B., and Beale M.H., (1997). Neural Network Design. PWS Publishing Co: Boston, MA, USA.

[4] Kreider J. F. and Wan X. A. (1991), "Artificial Neural Network demonstration for automated generation of energy use predictors for commercial buildings", ASHRAE Transactions, 97 (2), pp. 775-779.
[5] Yorukoglu M. and A.N. Celik, (2006). "A critical review on the estimation of daily global solar radiation from sunshine duration", Energy Conversion and Management 47: 2441-2450.

[6] Okundamiya M.S. and Nzeako A.N., (2010). Empirical Model for Estimating Global Solar Radiation on Horizontal Surfaces for Selected Cities in the Six Geopolitical Zones in Nigeria. Research Journal of Applied Sciences, Engineering and Technology. 2(8): 805-812.

[7] Page J.K. (1961). The estimation of monthly mean values of daily total short wave radiation on vertical and inclined surface from sunshine records for latitudes $40 \mathrm{~N}-40 \mathrm{~S}$. Proceedings of UN Conference on New Sources of Energy, 4(598), 378-390.

[8] Prescott, J.A., (1940). Evaporation from a water surface in relation to solar radiation. Trans. R. Soc. Sci. Australia 64, 114 - 125. 